\title{
Plasma Ketosteroids and Testosterone in Man: A Study of the Pituitary-testicular Axis*
}

\author{
Marvin A. Kirschner, Mortimer B. Lipsett, $\dagger$ and David R. Collins \\ (From the Endocrinology Branch, National Cancer Institute, Bethesda, Md.)
}

The relationship between the Leydig cell of the testis and the tropic hormones of the anterior pituitary gland has been inadequately explored in man because of methodological difficulties. The development of methods for measuring plasma testosterone ${ }^{1}$ levels in this and other laboratories has made such studies possible. We have examined the ability of the Leydig cell to respond to stimulation by gonadotropin, its inhibition by exogenous androgen, diurnal variation of plasma testosterone, and the role of the adrenal cortex in the maintenance of plasma testosterone levels in man.

To measure plasma testosterone, we have used a double isotope derivative method and employed gas-liquid chromatography as the final chromatographic step. This method has also been applied to the measurement of the plasma levels of dehydroepiandrosterone, androsterone, and etiocholanolone. The methods will be presented in detail, and we shall show that the relationship between the testicular Leydig cell and the anterior pituitary gland is similar to the relationship between the adrenal cortex and the anterior pituitary gland.

\section{Methods}

The plasma steroids were measured by a double isotope derivative method using $\mathrm{C}^{\mathbf{1 4}}$-labeled steroids to monitor recovery and $\mathrm{H}^{3}$-acetic anhydride to measure mass.

\footnotetext{
* Submitted for publication August 12, 1964 ; accepted December 28, 1964.

† Send requests for reprints to: Dr. Mortimer B. Lipsett, Endocrinology Branch, National Cancer Institute, Bethesda, Md. 20014.

1 The following trivial names have been used: testosterone, $17 \beta$-hydroxy-4-androsten-3-one ; dehydroepiandrosterone, $3 \beta$-hydroxy-5-androsten-3-one; androstenedione, 4 -androsten-3,17-dione; androsterone, $3 \alpha$-hydroxy-5 $\alpha$-androstan-17-one; etiocholanolone, $3 \alpha$-hydroxy- $5 \beta$-androstan-17-one ; epitestosterone, 17 $\alpha$-hydroxy-4-androsten-3one; epiandrosterone, $3 \beta$-hydroxy- $5 \alpha$-androstan-17-one ; cortisol, 11 $\beta-17 \alpha, 21$-trihydroxy-4-pregnen-3,20-dione.
}

$\mathrm{C}^{14}$-labeled steroids were added, plasma was extracted, and the steroids were separated by thin-layer and paper chromatography. After acetylation and thin-layer chromatography, final purification was achieved with gasliquid chromatography The effluent was collected and the isotopes were counted.

Materials. Testosterone-4-C $\mathrm{C}^{14}$ (SA, $22 \mathrm{mc}$ per mmole) ${ }^{2}$ and dehydroepiandrosterone-4- $\mathrm{C}^{14}$ (SA, $50 \mathrm{mc}$ per mmole $)^{2}$ were chromatographed in the Bush system, A1, and on thin-layer silica gel before use. The final material had less than $2 \%$ impurity on the basis of gas-liquid chromatography. Specific activities were determined by liquid scintillation counting and gas-liquid chromatography. In general, the specific activities agreed closely with those given by the supplier.

Androsterone-4- $\mathrm{C}^{14}$ and etiocholanolone-4-C $\mathrm{C}^{14}$ were isolated from the urine of an orchiectomized, hypophysectomized man who had received testosterone-4- $\mathrm{C}^{\mathbf{1 4}}$ and were purified as above. SA of androsterone was $23 \mathrm{mc}$ per mmole and of etiocholanolone, $21 \mathrm{mc}$ per mmole determined as above.

Acetic anhydride-1- $\mathrm{H}^{3}$ (SA, $100 \mathrm{mc}$ per mmole) ${ }^{2}$ was standardized with both testosterone-4- $\mathrm{C}^{14}$ and dehydroepiandrosterone-4- $\mathrm{C}^{14}$. The procedure was identical to that to be described for the plasma steroid determinations. The 2 SD counting error of the specific activity was $7 \%$.

Solvents. All the solvents were redistilled before use. The acetone was purified by adding a small amount of potassium permanganate before distillation.

Thin-layer chromatography. Thin-layer plates, $20 \times 20$ $\mathrm{cm}$ and $20 \times 45 \mathrm{~cm}$, were coated to a thickness of 0.375 $\mathrm{mm}$ with silica gel G. ${ }^{3}$ The developing systems used were benzene: ethyl acetate $(60: 40), \mathrm{B} 6$, and benezene: ethyl acetate $(80: 20)$, B8. The long plates were developed 3.5 hours and the short plates for 45 minutes. Appropriate areas were eluted twice with $5 \mathrm{ml}$ of acetone.

Paper chromatography. Whatman 1 filter paper was washed as previously described (1). Chromatograms were equilibrated for at least 5 hours and developed for 10 hours in the Bush type system A1, ligroin: methanol: water $(100: 90: 10)$ and $A 2$, ligroin: methanol: water $(100: 70: 30)$, and in the Decalin system, Decalin : nitromethane: methanol $(100: 50: 50)$.

Gas-liquid chromatography. A dual column gas chromatographic system was adapted with an effluent frac-

\footnotetext{
2 New England Nuclear Corp., Boston, Mass.

${ }^{3}$ Brinkman Instruments, Great Neck, N. Y.

4 Glowall Corp., Glenside, Pa.
} 
tion collector ${ }^{5}$ after the design of Karmen, McCaffrey, Winkleman, and Bowman (2). The 6-foot glass spiral columns of $3.4 \mathrm{~mm}$ i.d. were packed with gaschrome $\mathrm{P}$, 60 to 80 mesh, coated with $2.5 \%$ SE- $30^{6}$ prepared by the filtration technique (3). A Lovelock radium foil argon ionization detector was operated at 600 to $800 \mathrm{v}$ with an argon input pressure of 20 pounds per square inch resulting in a flow of $25 \mathrm{ml}$ per minute.

After passing through the detector, the effluent was adsorbed on recrystallized $p$-terphenyl 5 coated with $5 \%$ DC- $550^{6}$ (2). The packed cartridges were moved into collecting position on a manual signal given when the peak appeared on the recorder. Recovery of radioactivity from the column was 50 to $75 \%$. There was no significant radioactivity eluted from the column because of previous chromatography of labeled samples.

The $p$-terphenyl was emptied into counting vials and $5 \mathrm{ml}$ of toluene containing $0.4 \%$ diphenyloxazole (PPO) and $0.05 \%$ 1,4-bis-2-(5-phenyloxazolyl) benzene $(\mathrm{POPOP})^{7}$ was added. The $p$-terphenyl does not completely dissolve, but the steroid is completely eluted into the toluene and quenching is not observed. Counting was done in a Packard Tri-Carb liquid scintillation spectrometer, model $314 \mathrm{EX}$, operating at $18.4 \%$ efficiency for $\mathrm{H}^{3}$ and $46 \%$ for $\mathrm{C}^{14}$ with discrimination and gain settings such that less than $0.4 \%$ of the $\mathrm{H}^{3}$ was counted in the $\mathrm{C}^{14}$ channel. Sufficient counts were accumulated so that the $2 \mathrm{SD}$ counting error for the $\mathrm{H}^{3} / \mathrm{C}^{14}$ was less than $5 \%$.

Procedure in detail. Heparinized plasma was separated from red cells within 0.5 hours of withdrawal and stored at $-16^{\circ} \mathrm{C}$ until processed. Twenty $\mathrm{ml}$ of plasma was obtained from men and $40 \mathrm{ml}$ from women. About $5,000 \mathrm{dpm}(0.03 \mu \mathrm{g})$ of the appropriate $\mathrm{C}^{14}$-labeled steroids was added to the plasma and thoroughly mixed. Before extraction $1 \mathrm{ml}$ of $1 \mathrm{~N} \mathrm{NaOH}$ per $40 \mathrm{ml}$ plasma was added and the plasma then extracted twice with equal volumes of ether:chloroform (3:1). After washing once with water, the solvent was removed under reduced pressure.

The extract was chromatographed in system B6 on long plates with appropriate standards. Generally, two samples could be applied to a single plate. Androsterone and dehydroepiandrosterone are eluted together $\left(R_{f}\right.$ 0.40 ), and etiocholanolone and testosterone are eluted together ( $R_{f} 0.32$ and 0.30 , respectively).

Separation of androsterone and dehydroepiandrosterone was completed by chromatography in Bush A1. Testosterone and etiocholanolone were similarly separated in Bush A2. Each steroid was then chromatographed on short plates in system B6 in order to remove nonspecific paper contaminants.

The eluates were dried in 15-ml glass-stoppered centrifuge tubes. Acetylation was performed with $10 \mu 1$ of pyridine and $10 \mu \mathrm{l}$ of $20 \%$ acetic anhydride $-1-\mathrm{H}^{3}$ in benzene and overnight incubation at $37^{\circ} \mathrm{C}$.

5 Packard Instruments Co., La Grange, Ill.

6 Applied Science Laboratories, State College, Pa.

7 Pilot Chemicals, Watertown, Mass.
One $\mathrm{ml}$ of $20 \%$ ethanol was added to terminate acetylation. After addition of $50 \mu \mathrm{g}$ of unlabeled steroid acetate, the steroids were extracted with $10 \mathrm{ml}$ of methylene chloride. The $\mathrm{MeCl}_{2}$ was washed once with 0.1 vol of 1 $\mathrm{N} \mathrm{NaOH}$, with $\mathrm{H}_{2} \mathrm{O}$ until neutral, and dried over sodium sulfate. The testosterone acetate was applied to a silica gel plate and developed in B8. The band was located by spraying with a $0.2 \%$ solution of rhodamine $6 \mathrm{G} .8$ The testosterone acetate eluate was dried under air, dissolved in acetone, and a 40 to $60 \%$ sample used for gasliquid chromatography.

The ketosteroid acetates were chromatographed in the Decalin system and located by the Zimmermann reaction of the appropriate standards. They were eluted with acetone-methanol and chromatographed in system B8. Gas-liquid chromatography was then performed as above. Dimethylhydrazones. The 1,1-N-dimethylhydrazones (4) of the steroid acetates were formed by adding $0.5 \mathrm{ml}$ of 1,1-N-dimethylhydrazine ${ }^{9}$ and 1 drop of glacial acetic acid to the dried sample. The solution was heated at $56^{\circ} \mathrm{C}$ for 5 minutes, and after standing overnight at room temperature the reagents were removed under a stream of $\mathrm{N}_{2}$, the dimethylhydrazones taken up in ethyl acetate, and a sample used for gas-liquid chromatography. The dimethylhydrazones of the ketosteroid acetates were formed in $90 \%$ yield. However, the reaction with testosterone acetate was not complete, and yields of 40 to $60 \%$ were obtained. The separation factor of the dimethylhydrazone from the parent steroid acetates is 1.3 on SE-30.

Calculations. The steroid content of the sample is calculated by the expression, micrograms per sample = $\left(\mathrm{H}^{3} / \mathrm{C}^{14}\right)\left(\mathrm{C}^{14} / \mathrm{SA}\right)-\mathrm{t}$, where the $\mathrm{H}^{3} / \mathrm{C}^{14}$ ratio is that obtained after gas-liquid chromatography, $C^{14}$ is the counts per minute of steroid added, SA is the specific activity of the acetic anhydride expressed as counts per minute per microgram of steroid, and $t$ is the micrograms of steroid added to the plasma as internal standard.

\section{Comments on method}

It was apparent during the development of this procedure that after acetylation, the removal of excess tritium constituted a major obstacle to the determination of the $\mathrm{H}^{3} / \mathrm{C}^{14}$ ratio of the steroids. This problem had been solved previously by the use of multiple paper and thin-layer chromatographic systems The higher resolving capacity of gas-liquid chromatography made it a useful adjunct for this purpose. In Table I, the reduction of the tritium counts is shown for each chromatographic step. It is evident that gas-liquid chromatography reduced $\mathrm{H}^{3}$ contamination to a greater extent than conventional chromatography so that the final $\mathrm{H}^{3} / \mathrm{C}^{14}$ ratio is attained in fewer steps. In the case of dehydroepiandrosterone, however, interposition of the Decalin paper system was necessary to reduce $\mathrm{H}^{3}$ contaminants. In each case the dimethylhydrazones had the same $\mathrm{H}^{3} / \mathrm{C}^{14}$ ratio as the corresponding

8 Allied Chemical Corp., New York, N. Y.

${ }^{\boldsymbol{9}}$ Eastman Organic Chemicals, Rochester, N. Y. 
TABLE I

Removal of excess tritium during purification procedures

\begin{tabular}{|c|c|c|c|}
\hline & \multicolumn{3}{|c|}{$\mathrm{H}^{2} / \mathrm{C}^{14}$ ratios } \\
\hline & $\begin{array}{l}\text { Dehydroepi- } \\
\text { androsterone } \\
\text { in water }\end{array}$ & $\begin{array}{c}\text { Dehydroepi- } \\
\text { androsterone } \\
\text { in plasma }\end{array}$ & $\begin{array}{c}\text { Testosterone } \\
\text { in plasma }\end{array}$ \\
\hline $\begin{array}{l}\text { Step } 1 \\
\text { Washing only after } \\
\text { acetylation } \\
\text { Gas-liquid chromatography }\end{array}$ & $\begin{array}{l}1.10 \\
0.36\end{array}$ & $>100$ & $>100$ \\
\hline $\begin{array}{l}\text { Step } 2 \\
\text { After paper chroma- } \\
\text { tography } \\
\text { Gas-liquid chromatography }\end{array}$ & $\begin{array}{l}0.37 \\
0.33\end{array}$ & $\begin{array}{r}58.0 \\
8.4\end{array}$ & \\
\hline $\begin{array}{l}\text { Step } 3 \\
\text { After thin-layer chroma- } \\
\text { tography } \\
\text { Gas-liquid chromatography }\end{array}$ & $\begin{array}{l}0.39 \\
0.33\end{array}$ & $\begin{array}{r}15.0 \\
4.5\end{array}$ & $\begin{array}{r}14.9 \\
2.7\end{array}$ \\
\hline $\begin{array}{l}\text { Step } 4 \\
\text { Gas-liquid chromatography } \\
\text { of dimethylhydrazone }\end{array}$ & 0.34 & 4.5 & 2.8 \\
\hline
\end{tabular}

steroid acetate. When these steroids are measured routinely, dimethylhydrazones are not prepared, since there has been consistent agreement between the $\mathrm{H}^{3} / \mathrm{C}^{14}$ ratios of the acetates and the hydrazones.

Precision. The theoretical error of the method, calculated from a consideration of the estimated errors of the individual steps, was $8 \% .{ }^{10}$ These errors include the calculation of specific activities of the internal standards and the acetic anhydride and the counting and sampling errors. The precision of the method was determined from multiple determinations of the steroids of pooled plasma from men and women and duplicate determinations of several plasma samples (Table II). Although the coefficients of variation for androsterone and etiocholanolone were $15 \%$, this precision is quite adequate for most physiologic studies. The coefficients of variation for plasma dehydroepiandrosterone and for plasma testosterone in men are low. The measurement of the plasma testosterone level in normal women has a coefficient of variation of $20 \%$.

Accuracy. The recovery of steroids added to plasma is shown in Table III. When the plasma testosterone level was in the male range ( 0.5 to $1.0 \mu \mathrm{g}$ per $100 \mathrm{ml}$ ), recoveries of added testosterone were near $100 \%$. At plasma levels of $0.01 \mu \mathrm{g}$ per $100 \mathrm{ml}$, the recovery of $0.05 \mu \mathrm{g}$ was $88 \%$. The recovery of added dehydroepiandrosterone at physiological levels ranged from 96 to $109 \%$.

The yield of $\mathrm{C}^{14}$ after gas-liquid chromatography was 100 to $300 \mathrm{cpm}$. Since the $\mathrm{H}^{3} / \mathrm{C}^{14}$ ratios varied from $1: 1$ to $4: 1$ for testosterone acetate, both $\mathrm{H}^{3}$ and $\mathrm{C}^{14}$ could be measured with an error of $5 \%$ ( $2 \mathrm{SD}$ ).

Sensitivity. The blank value of the method was determined with either water or plasma obtained from pa-

$10 \mathrm{We}$ gratefully acknowledge the assistance of Dr. Marvin Zelen, Experimental Statistics Branch, National Cancer Institute. tients who had had ablative endocrine procedures for breast cancer. For dehydroepiandrosterone, androsterone, and etiocholanolone, the blank value was about $0.1 \mu \mathrm{g}$ per $100 \mathrm{ml}$. Thus these steroids can be measured at a level of $0.2 \mu \mathrm{g}$ with an accuracy of $17 \%$. The testosterone blank was $0.01 \mu \mathrm{g}$ per $100 \mathrm{ml}$. Water blanks were run with each set of determinations and these values subtracted from the values for the steroids measured. Since these data were obtained with the addition of 0.03 $\mu \mathrm{g}$ of testosterone- $\mathrm{C}^{\mathbf{1 4}}$ to $\mathbf{4 0} \mathrm{ml}$ of plasma, the sensitivity of the determination is limited by that factor, and $0.05 \mu \mathrm{g}$ of testosterone per $100 \mathrm{ml}$ of plasma can be measured with an accuracy of about $25 \%$. This sensitivity has been improved recently by using testosterone of higher specific activity so that the amount of testosterone now added to plasma is $0.003 \mu \mathrm{g}$.

Specificity. The fact that the water and plasma blanks were the same (Table IV) indicates that other plasma components were not being measured. Several known

TABLE II

Precision of method

\begin{tabular}{ccc}
\hline & $\begin{array}{c}\text { No. } \\
\text { samples }\end{array}$ & $\begin{array}{c}\text { Coeff- } \\
\text { cient of } \\
\text { variation }\end{array}$ \\
\hline Testosterone & & $\%$ \\
Range: $<0.10^{*}$ & 14 & 20 \\
0.10 to 0.50 & 12 & 12 \\
0.5 to 2.0 & 25 & 7 \\
Dehydroepiandrosterone & 15 & 9 \\
Range: $<1.0-1.0$ & 26 & 5 \\
$\quad>1.0$ & 22 & 15 \\
Etiocholanolone & & \\
Range: $0.29-2.1$ & 4 & 15 \\
Androsterone & & \\
Range: $0.15-0.45$ & &
\end{tabular}

* $\mu \mathrm{g}$ per $100 \mathrm{ml}$ plasma. 
TABLE III

Recovery studies

\begin{tabular}{|c|c|c|c|c|c|}
\hline $\begin{array}{l}\text { Study } \\
\text { no. }\end{array}$ & Determined & Added & Expected & Found & $\%$ recovered \\
\hline \multicolumn{6}{|c|}{$\begin{array}{l}0 \mathrm{ml} \mu \mathrm{m} / \mathrm{100} \\
\text { Testosterone }\end{array}$} \\
\hline $\begin{array}{l}1 \\
2 \\
3 \\
4\end{array}$ & $\begin{array}{l}0.42 \pm 0.04^{*}(3) \dagger \\
0.54 \pm 0.03(4) \\
0.53 \pm 0.05(4) \\
0.011 \pm 0.005(3)\end{array}$ & $\begin{array}{l}0.50 \\
0.50 \\
1.0 \\
0.050\end{array}$ & $\begin{array}{l}0.92 \\
1.04 \\
1.53 \\
0.061\end{array}$ & $\begin{array}{l}0.94 \pm 0.01(3) \\
1.07 \pm 0.02(3) \\
1.53 \pm 0.03(4) \\
0.053 \pm 0.007(3)\end{array}$ & $\begin{array}{r}102 \\
103 \\
100 \\
88\end{array}$ \\
\hline \multicolumn{6}{|c|}{ Dehydroepiandrosterone } \\
\hline $\begin{array}{l}1 \\
2\end{array}$ & $\begin{array}{l}1.61 \pm 0.29(3) \\
1.26 \pm 0.06(3)\end{array}$ & $\begin{array}{l}1.0 \\
1.0\end{array}$ & $\begin{array}{l}2.61 \\
2.26\end{array}$ & $\begin{array}{l}2.50 \pm 0.08 \\
2.46 \pm 0.05\end{array}$ & $\begin{array}{r}96 \\
109\end{array}$ \\
\hline
\end{tabular}

* Standard deviation.

$\dagger$ No. of samples.

plasma steroids such as epiandrosterone, epitestosterone, and androstenedione were separated before acetylation. When these steroids and androsterone, etiocholanolone, and dehydroepiandrosterone were added to water, the testosterone blank was unchanged. Finally, gas-liquid chromatography of the acetates and the dimethylhydrazones gave $\mathrm{H}^{3} / \mathrm{C}^{14}$ ratios that were in agreement. The classical criterion of uniform ratios throughout the peak could not be met, since isotope fractionation occurs during gasliquid chromatography. (5). Thus the $\mathrm{H}^{3} / \mathrm{C}^{14}$ ratio of the entire peak must be used.

\section{Results}

The plasma steroid levels in a group of normal adults ranging in age from 18 to 44 are listed in Table V. Plasma testosterone concentration in men ranged from 0.44 to $1.30 \mu \mathrm{g}$ per $100 \mathrm{ml}$ with a mean value of $0.74 \mu \mathrm{g}$ per $100 \mathrm{ml}$ and SD of 0.26 . Testosterone levels were also measured in a group of ten women; the mean was $0.07 \mu \mathrm{g}$ per $100 \mathrm{ml}$ (range, 0.02 to 0.12 ). Free dehydroepiandrosterone levels were more nearly equal in men and women, averaging $1.3 \mu \mathrm{g}$ per $100 \mathrm{ml}$ in 15 men and 1.0 in ten women. In a limited series, plasma etiocholanolone and androsterone values were higher in men than women.

TABLE IV

Blank values

\begin{tabular}{lll}
\hline \hline & \multicolumn{1}{c}{ From water } & From plasma* \\
\hline & \multicolumn{1}{c}{$\mu \mathrm{g} / 100 \mathrm{ml}$} & $\mu \mathrm{gg} / 100 \mathrm{ml}$ \\
Testosterone & $0.010 \pm 0.006(13) \dagger$ & $\mathbf{0 . 0 1 0 , 0 . 0 1 2}$ \\
Dehydroepiandrosterone & $0.09 \pm 0.04(9)$ & $\mathbf{0 . 1 1}, 0.08$ \\
Androsterone & $0.13,0.15$ & 0.15 \\
Etiocholanolone & $0.12 \pm 0.03(4)$ & 0.14
\end{tabular}

* Values from ovariectomized, hypophysectomized women. † No. of determinations.
In four men plasma testosterone was measured on two separate occasions, several weeks apart. The coefficient of biologic variation in these samples was $16 \%$. In a similar study, dehydroepiandrosterone was determined on each of three occasions in four subjects. Coefficient of variation was $10 \%$.

Diurnal variation. The fluctuation of plasma testosterone and dehydroepiandrosterone during the day was studied by measuring these levels at 8 a.m. and 4 p.m. in a group of nine subjects, as indicated in Figure 1. The mean values for plasma testosterone in this group were $0.71 \mu \mathrm{g}$ per $100 \mathrm{ml}$ at 8 a.m. and $0.69 \mu \mathrm{g}$ per $100 \mathrm{ml}$ at 4 p.m. The average value for plasma dehydroepiandrosterone was $26 \%$ lower in the afternoon than in the morning.

Gonadotropin stimulation. Plasma testosterone levels were measured acutely after a single intramuscular injection of human chorionic gonadotropin (HCG) ${ }^{11}$ and after prolonged HCG stimulation. Plasma testosterone levels did not increase after a single injection of $1,000 \mathrm{U}$ of HCG (Figure 2). However, with 2,000 U of $\mathrm{HCG}$, an increase in plasma testosterone was seen within 6 hours in four of five subjects and was apparent at 2 hours in three subjects. Twentyfour hours after the injection, the plasma testosterone level had returned to normal in two of the three subjects.

When HCG was given daily in doses of 1,000 to $2,000 \mathrm{U}$, there was at least a doubling of the plasma testosterone concentration (Table VI).

11 Ayerst Laboratories, New York, N. Y. 


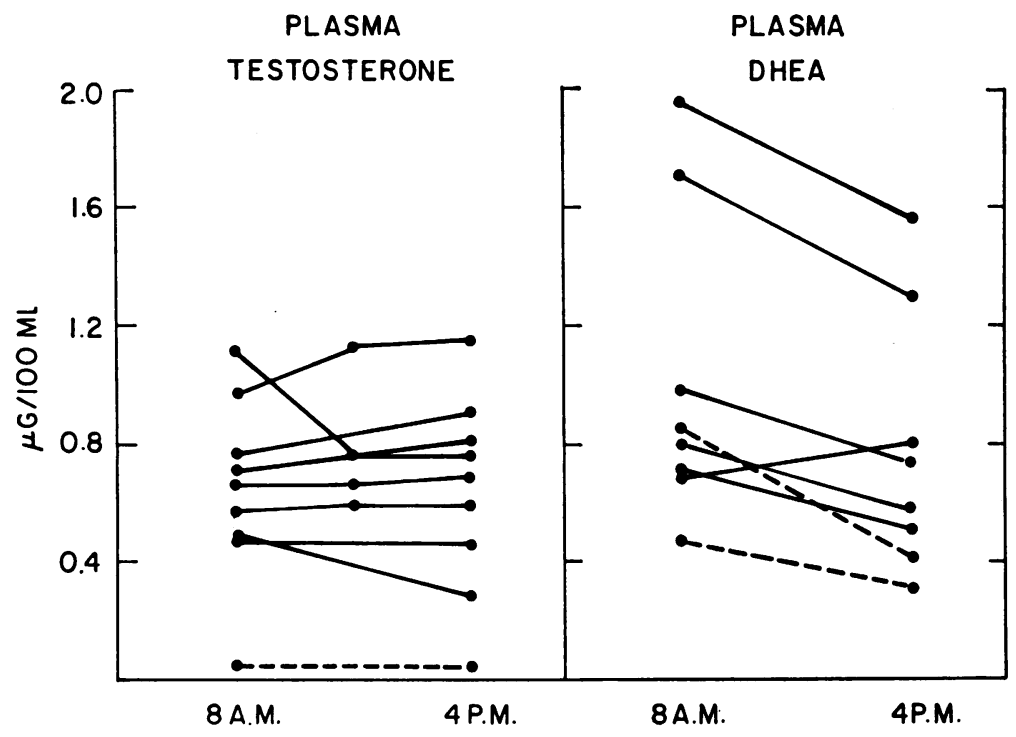

Fig. 1. Plasma levels of testosterone and Dehydroepiandrosterone (DHEA) AT 8 A.M. AND 4 P.M. Solid lines represent men; dotted lines, women.

Similar doses of HCG for 3 to 5 days were without effect in four normal women.

Plasma dehydroepiandrosterone levels were unchanged by HCG stimulation in both men and women (Table VI). Plasma etiocholanolone levels, measured in two men, increased from only 0.69 and $1.0 \mu \mathrm{g}$ per $100 \mathrm{ml}$ to 0.94 and $1.1 \mu \mathrm{g}$ per $100 \mathrm{ml}$, respectively.

Fluoxymesterone ( $9 \alpha$-fluoro-11 $\beta$-hydroxy-17 $\alpha$ methyltestosterone), a synthetic androgen 70 to $80 \%$ as potent as testosterone, was given to four men at dose levels of $10 \mathrm{mg}$ and $40 \mathrm{mg}$ daily for 3 days. The data, summarized in Figure 3, show that the lower dose of fluoxymesterone resulted in a $50 \%$ decrease in plasma testosterone levels. The levels were further decreased to $80 \%$ of the control values with the higher dose of fluoxymesterone. By comparison, plasma dehydroepiandrosterone levels remained unchanged during these periods.

Effect of ACTH and prednisone. The effects of stimulation and suppression of the adrenal cortex are presented in Table VII. Prednisone caused an irregular decrease in plasma testosterone levels averaging $21 \%$ with four of the six subjects demonstrating this decrease. The effects of ACTH stimulation were less conclusive, and only two of the four subjects had a higher plasma testosterone level after stimulation. By contrast prednisone caused a $69 \%$ decrease in plasma dehydroepiandrosterone levels, and ACTH produced large increases in two of four subjects.

TABLE V

Normal values for plasma steroids

\begin{tabular}{|c|c|c|c|c|c|c|c|}
\hline \multicolumn{2}{|c|}{ Testosterone } & \multicolumn{2}{|c|}{ Dehydroepiandrosterone } & \multicolumn{2}{|c|}{ Androsterone } & \multicolumn{2}{|c|}{ Etiocholanolone } \\
\hline Men & Women & Men & Women & Men & Women & Men & Women \\
\hline \multicolumn{2}{|c|}{$\mu \mathrm{g} / 100 \mathrm{ml}$ plasma } & \multicolumn{2}{|c|}{$\mu \mathrm{g} / 100 \mathrm{ml}$ plasma } & \multicolumn{2}{|c|}{$\mu \mathrm{g} / 100 \mathrm{ml}$ plasma } & \multicolumn{2}{|c|}{$\mu \mathrm{g} / 100 \mathrm{ml}$ plasma } \\
\hline No. subjects & 10 & 15 & 10 & 2 & 4 & 7 & 4 \\
\hline $\begin{array}{l}\text { Mean } \\
0.74 \pm 0.26^{*} \\
\text { Range }\end{array}$ & $0.07 \pm 0.03$ & $1.28 \pm 0.47$ & $1.04 \pm 0.38$ & 0.41 & $0.20 \pm 0.05$ & $0.62 \pm 0.17$ & $0.31 \pm 0.02$ \\
\hline $0.44-1.30$ & $0.02-0.12$ & $0.60-2.0$ & $0.45-1.66$ & $0.37,0.45$ & $0.15-0.25$ & $0.35-0.77$ & $0.29-0.33$ \\
\hline
\end{tabular}

* Standard deviation. 


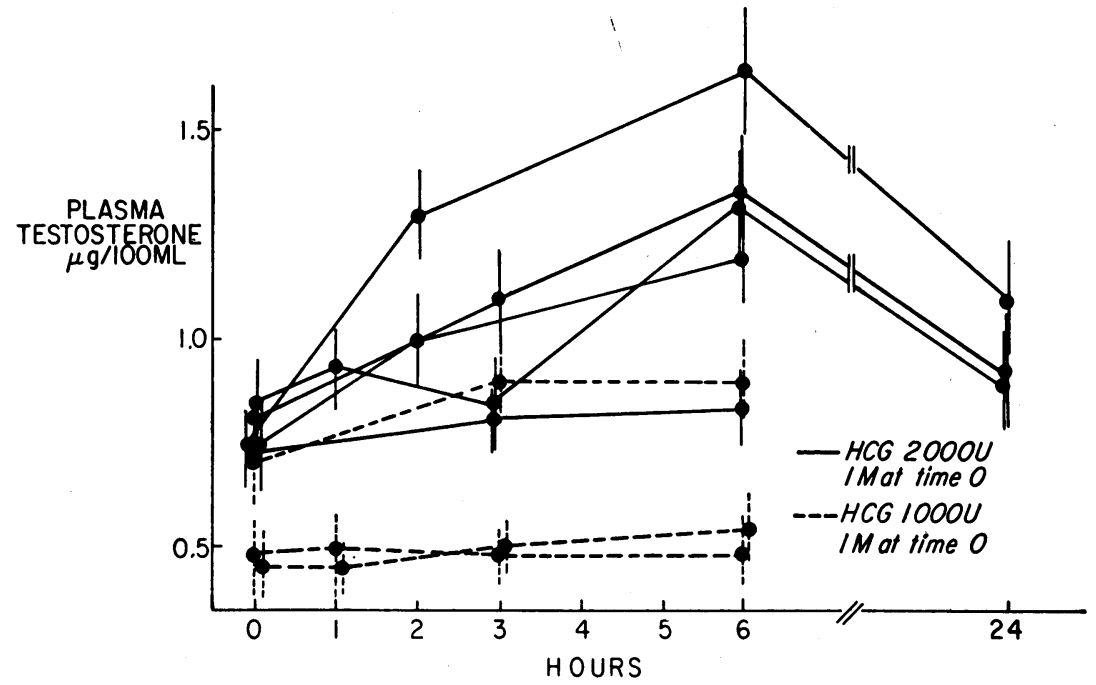

Fig. 2. ACUte Responses of plasma testosterone levels to human Chorionic Gonadotropin (HCG). Vertical bars give $95 \%$ confidence limits of the values.

\section{Discussion}

The plasma testosterone levels of the adult male are quite comparable to those reported by others using either double isotope derivative techniques $(6-8)$ or the fluorescence of the estrogen formed from testosterone (9). The reliability of the present method for studies of Leydig cell physiology is adequate.

Plasma testosterone levels in women have been in the range of $0.1 \mu \mathrm{g}$ per $100 \mathrm{ml}(6,7,9)$ except for those reported by Riondel and his colleagues (8), who used a $S^{35}$-double isotope derivative technique. Their normal values were close to ours, and the error of $30 \%$ was the same in both studies. The present method cannot be used to measure relatively minor changes in plasma testosterone at the $0.05-\mu \mathrm{g}$ level, but is adequate to measure those disturbances of androgen metabolism that result in elevated plasma levels.

The plasma levels of the 17 -ketosteroids have been measured in a limited number of subjects by Cohn, Bondy, and Castiglione (10). The range of their plasma dehydroepiandrosterone levels was $<0.5 \mu \mathrm{g}$ to $1.2 \mu \mathrm{g}$ per $100 \mathrm{ml}$, whereas the mean plasma dehydroepiandrosterone level in our study averaged $1.2 \mu \mathrm{g}$ per $100 \mathrm{ml}$. Recently Gandy and Peterson (11) have reported that plasma dehydroepiandrosterone ranged between 0.21 and $1.59 \mu \mathrm{g}$ per $100 \mathrm{ml}$. It seems probable that the discrepancy between the earlier report and the latter two is methodological, since Cohn and associates employed a colorimetric determination used at maximal sensitivity. The

TABLE VI

Effect of chronic HCG administration on plasma steroids in men

\begin{tabular}{|c|c|c|c|c|c|c|}
\hline & \multirow{2}{*}{$\begin{array}{c}\text { Days of } \\
\text { treatment }\end{array}$} & \multirow[b]{2}{*}{ Dose } & \multicolumn{2}{|c|}{ Testosterone } & \multicolumn{2}{|c|}{ Dehydroepiandrosterone } \\
\hline & & & Control & Treated & Control & Treated \\
\hline & \multirow{9}{*}{$\begin{array}{r}3 \\
3 \\
10 \\
5 \\
5 \\
3 \\
5\end{array}$} & \multirow{9}{*}{$\begin{array}{c}I U / \text { day } \\
1,000 \\
1,000 \\
2,000 \\
1,000 \\
1,000 \\
1,000 \\
1,000\end{array}$} & \multicolumn{2}{|c|}{$\mu \mathrm{g} / 100 \mathrm{ml}$} & \multicolumn{2}{|c|}{$\mu \mathrm{g} / 100 \mathrm{ml}$} \\
\hline W. R. & & & 1.30 & \multirow{8}{*}{$\begin{array}{l}2.90 \\
2.30 \\
1.56 \\
1.73 \\
1.35 \\
1.40 \\
1.75 \\
1.77\end{array}$} & 1.75 & 2.1 \\
\hline C. C. & & & 1.10 & & 1.75 & 1.50 \\
\hline L. F. & & & 0.75 & & & \\
\hline M. $\dot{\mathrm{K}}$. & & & 0.90 & & 1.40 & 1.73 \\
\hline T. D. & & & 0.45 & & 0.81 & 0.70 \\
\hline A. H. I & & & 0.84 & & 1.56 & 1.48 \\
\hline II & & & & & & \\
\hline Mean & & & 0.86 & & 1.44 & 1.14 \\
\hline
\end{tabular}


limited numbers of values for plasma androsterone and etiocholanolone do not warrant further comparison.

The diurnal variation in plasma cortisol levels has been known for many years (12), but similar observations of plasma testosterone or the 17-ketosteroids have not been possible. The data obtained from eight men are evidence against the existence of a significant diurnal variation of the plasma testosterone levels. Plasma dehydroepiandrosterone concentration, however, was lower at 4 p.m. than at 8 a.m. Since plasma dehydroepiandrosterone probably originates in large part from the adrenal cortex, it is not unexpected that plasma dehydroepiandrosterone and cortisol have the same diurnal variation. It would nevertheless be premature to conclude that there is no consistent fluctuation of interstitial cell stimulating hormone similar to that of ACTH (13) since the changes may be within a smaller range or may be masked by opposing alterations in the disposal of testosterone.

Although dehydroepiandrosterone has been isolated from the testis (14) and found in spermatic vein blood (15), it seems clear that dehydroepiandrosterone and dehydroepiandrosterone sulfate are largely derived from the adrenal cortex. The increase and decrease in plasma dehydroepiandrosterone levels resulting from administration of ACTH and prednisone, respectively, are in accord with this. The administration of $20 \mathrm{mg}$ of prednisone daily does not represent maximal adrenal cortical suppression, so that the remaining fraction of the plasma dehydroepiandrosterone may still originate from the adrenal cortex.

The smaller decrease in plasma testosterone
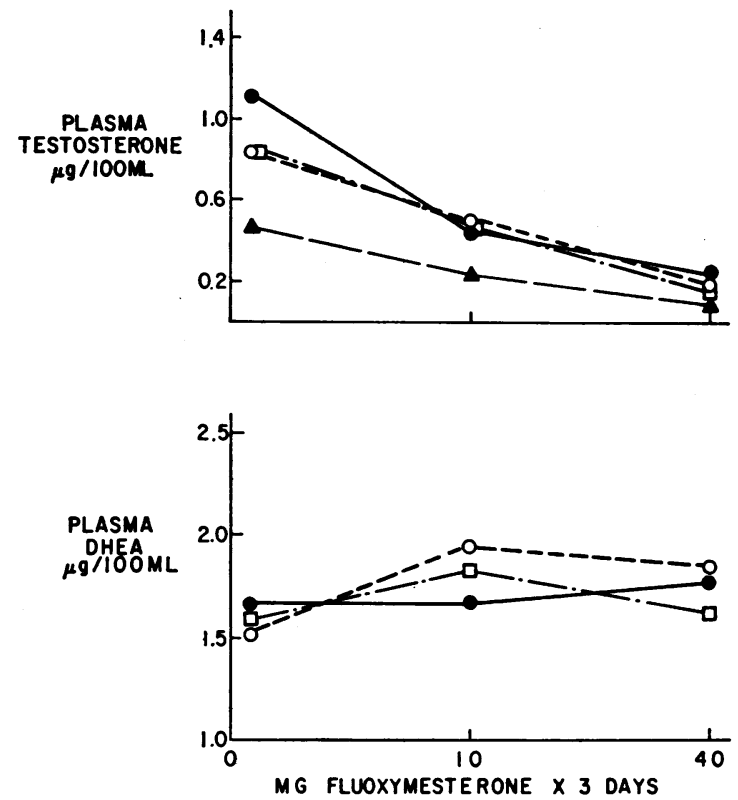

Fig. 3. Response of plasma levels of testosterone AND DEHYDROEPIANDROSTERONE TO SUPPRESSIVE DOSES OF ANDROGEN. Vertical bars give $95 \%$ confidence limits.

level during prednisone administration was expected. It has been shown that the adrenal cortex has the capacity for testosterone synthesis (16) and that steroids such as androstenedione and dehydroepiandrosterone, which are secreted by the adrenal cortex, can be metabolized in part to testosterone by peripheral tissue (17-19). However, in the male, the major fraction of testosterone production results from testicular secretion of testosterone, so that adrenal cortical suppression would be expected to produce only small changes in the plasma testosterone level. These data are in accord with the vast body of biologic evidence

TABLE VII

Effect of ACTH and prednisone in plasma steroids of men

\begin{tabular}{|c|c|c|c|c|c|c|}
\hline \multirow[b]{2}{*}{ Subject } & \multicolumn{3}{|c|}{ Testosterone } & \multicolumn{3}{|c|}{ Dehydroepiandrosterone } \\
\hline & Control & ACTH* & Prednisone & $\overline{\text { Control }}$ & ACTH* & Prednisone \\
\hline & \multicolumn{3}{|c|}{$\mu \mathrm{g} / 100 \mathrm{ml}$} & \multicolumn{3}{|c|}{$\mu \mathrm{g} / 100 \mathrm{ml}$} \\
\hline W. R. & 1.30 & & 0.95 & 1.70 & & 0.58 \\
\hline C. C. & 1.00 & & 0.70 & 1.90 & & 0.42 \\
\hline M. L. & 0.70 & 0.65 & 0.72 & 1.56 & 1.92 & 1.00 \\
\hline T. D. & 0.45 & 1.32 & 0.48 & 0.81 & 4.9 & 0.24 \\
\hline M. K. & 0.90 & 1.50 & 0.75 & 1.40 & 1.50 & 0.35 \\
\hline A. $\mathrm{H}$. & 0.84 & 0.75 & 0.52 & 1.56 & 1.65 & 0.24 \\
\hline Mean & 0.87 & 1.00 & 0.69 & 1.49 & 2.49 & 0.47 \\
\hline
\end{tabular}

* Corticotrophin gel, $40 \mathrm{U}$ im daily for 5 days.

† Prednisone, $20 \mathrm{mg}$ daily for 3 days. 
that the testis is the important source of androgen in the mammal and that secretions from the normal adrenal cortex cannot substitute for the testicular secretion of androgen.

Recently, Davis, Lipsett, and Korenman (20) have shown that the production of testosterone is inhibited by exogenous androgen and that this inhibition is most probably due to suppression of pituitary interstitial cell stimulating hormone. These observations have been extended by the demonstration that plasma testosterone levels are likewise decreased by exogenous androgen. The $10-\mathrm{mg}$ dose of fluoxymesterone that was used is equivalent to 7 to $8 \mathrm{mg}$ of testosterone and thus only slightly exceeds the average testosterone production rate (21). Yet this dose resulted in a $50 \%$ reduction in plasma testosterone. When the dose of fluoxymesterone was increased to 40 $\mathrm{mg}$, the plasma testosterone level was decreased by $80 \%$. The residual testosterone is most probably derived in part from adrenal cortical secretions.

These preliminary studies suggest a parallel between the pituitary-adrenal cortical axis and the pituitary-Leydig cell axis. Stimulation with either ACTH or HCG intramuscularly causes increases in plasma cortisol or testosterone within a few hours, and chronic stimulation with smaller doses of each tropic hormone leads to a slower rise in the respective plasma steroid levels. Similarly, doses of corticoid or androgen in the physiologic range cause an approximate $50 \%$ decrease in the secretion of cortisol or testosterone, and this inhibition can be extended by the use of large amounts of corticoid or androgen. The physiologic significance of the capacity of the Leydig cell to respond acutely to the level of interstitial cell stimulating hormone remains to be defined.

\section{Summary}

1. A double isotope derivative method using gas-liquid chromatography is presented for the simultaneous measurement of unconjugated testosterone, dehydroepiandrosterone, androsterone, and etiocholanolone in plasma of man.

2. Plasma dehydroepiandrosterone levels showed a diurnal variation with a $26 \%$ decrease from morning to afternoon. No such changes were noted in plasma testosterone levels.
3. Plasma testosterone levels increased 2 to 6 hours after chorionic gonadotropin and were suppressed $50 \%$ with physiologic doses of exogenous androgens. This suppression was even more marked with higher doses. The similarities of the relationship of the Leydig cell to the anterior pituitary gland with the adrenal cortical-anterior pituitary axis have been pointed out.

4. The contribution of adrenal secretions to plasma testosterone and dehydroepiandrosterone levels in man was measured. Prednisone administration markedly lowered the plasma dehydroepiandrosterone level, but resulted in only a $21 \%$ decrease of plasma testosterone.

\section{References}

1. Wilson, H., M. B. Lipsett, and D. W. Ryan. Urinary excretion of $\Delta^{5}$-pregnenetriol and other $3 \beta$ hydroxy- $\Delta^{5}$ steroids by subjects with and without endocrine disease. J. clin. Endocr. 1961, 21, 1304.

2. Karmen, A., J. McCaffrey, J. W. Winkleman, and R. L. Bowman. Measurement of tritium in the effluent of a gas chromatography column. Analyt. Chem. 1963, 35, 536.

3. Haahti, E. O. A. Major Lipid Constituents of Human Skin Surfaces, with Special Reference to Gaschromatographic Methods. Torku, Finland, Mercatorin Kirjapaino, 1961.

4. Vanden Heuvel, W. J. A., and E. C. Horning. Gaschromatographic characterization of steroid ketones as N,N-dimethylhydrazones. Biochim. biophys. Acta (Amst.) 1963, 74, 560.

5. Kirschner, M. A., and M. B. Lipsett. Isotope effects in gas-liquid chromatography of steroids. J. Lipid Res. 1964, 6, 7.

6. Hudson, B., J. Coghlan, A. Dulmanis, M. Wintour, and I. Ekkel. The estimation of testosterone in biological fluids. I. Testosterone in plasma. Aust. J. exp. Biol. med. Sci. 1963, 41, 235.

7. Burger, H. G., J. R. Kent, and A. E. Kellie. Determination of testosterone in human peripheral and adrenal venous plasma. J. clin. Endocr. 1964, 24, 432.

8. Riondel, A., J. F. Tait, M. Gut, S. A. S. Tait, E. Joachim, and B. Little. Estimation of testosterone in human peripheral blood using $\mathrm{S}^{85}$-thiosemicarbazide. J. clin. Endocr. 1963, 23, 620.

9. Forchielli, E., G. Sorcini, M. S. Nightingale, N. Brust, R. I. Dorfman, W. H. Perloff, and G. Jacobson. Testosterone in human plasma. Analyt. Biochem. 1963, 5, 416.

10. Cohn, G. L., P. K. Bondy, and C. Castiglione. Studies on pyrogenic steroids. I. Separation, identification, and measurement of unconjugated dehydro- 
epiandrosterone, etiocholanolone and androsterone in human plasma. J. clin. Invest. 1961, 40, 400.

11. Gandy, H. M., and R. E. Peterson. Plasma levels of unconjugated $\Delta^{4}$-androstene-3,17-dione, dehydroisoandrosterone, etiocholanolone, androsterone and testosterone in man. Proc. Endocr. Soc. 46th Meeting, San Francisco, 1964, p. 54.

12. Bliss, E. L., A. A. Sandberg, D. H. Nelson, and K. Eik-Nes. The normal levels of 17-hydroxycorticosteroids in the peripheral blood of man. J. clin. Invest. 1953, 32, 818.

13. Ney, R. L., N. Shimizu, W. E. Nicholson, D. P. Island, and G. W. Liddle. Correlation of plasma ACTH concentration with adrenocortical response in normal human subjects, surgical patients, and patients with Cushing's disease. J. clin. Invest. 1963, 42, 1669.

14. Neher, R., and A. Wettstein. Occurrence of $\Delta^{5}-3 \beta$ hydroxysteroids in adrenal and testicular tissue. Acta endocr. (Kbh.) 1960, 35, 1.

15. Eik-Nes, K. B., and P. F. Hall. Isolation of dehydroepiandrosterone- $\mathrm{C}^{14}$ from dogs infused with
cholesterol-4-C $\mathrm{C}^{14}$ by the spermatic artery. Proc. Soc. exp. Biol. (N. Y.) 1962, 111, 280.

16. Kase, N., and J. Kowal. In vitro production of testosterone in a human adrenal homogenate. $\mathrm{J}$. clin. Endocr. 1962, 22, 925.

17. Mahesh, V. B., and R. B. Greenblatt. The in vivo conversion of dehydroepiandrosterone and androstenedione to testosterone in the human. Acta endocr. (Kbh.) 1962, 41, 400.

18. Korenman, S. G., and M. B. Lipsett. Is testosterone glucuronoside uniquely derived from plasma testosterone? J. clin. Invest. 1964, 43, 2125.

19. Camacho, A. M., and C. J. Migeon. Studies on the origin of testosterone in the urine of normal adult subjects and patients with various endocrine disorders. J. clin. Invest. 1964, 43, 1083.

20. Davis, T. E., M. B. Lipsett, and S. G. Korenman. Suppression of testosterone production by physiologic doses of androgen. J. clin. Endocr., in press.

21. Korenman, S. G., H. Wilson, and M. B. Lipsett. Testosterone production rates in normal adults. J. clin. Invest. 1963, 42, 1753. 